\title{
Prevalence of depression and associated factors among patients with type 2 diabetes mellitus in eastern Sudan
}

\author{
Saeed M. Omar ${ }^{*}$, Imad R. Musa², Maysoon B. Idrees ${ }^{1}$ and Ishag Adam³
}

\begin{abstract}
Background: Diabetes mellitus (DM) represents a global health threat and burden. It is associated with medical and psychological complications, especially depression. Depression among patients with DM may affect the general prognosis. Hence, we conducted a cross-sectional study in Gadarif, eastern Sudan to evaluate the prevalence of depression and its associated factors among patients with type 2 DM (T2DM).

Methods: We performed a cross-sectional study. Data on anthropometric parameters, demographic characteristics and blood glucose levels were collected via questionnaire. Depression was assessed using the Patient Health Questionnaire (PHQ-9).

Results: Three hundred and fifty patients with T2DM were enrolled in the study and 205 (58.6\%) were women. The median (interquartile range) age and duration of diabetes were 56.0 (14.0) years and 8 (8) years, respectively. The prevalence of depression in patients with T2DM was 35.6\%. Logistic regression analysis showed significant associations between depression and rural residence (adjusted odds ratio $[A O R]=2.11,95 \%$ confidence interval $[C l]=1.20-3.72)$, non-employee $(A O R=2.32,95 \% C l=1.34-4.00)$, co-morbidity $(A O R=2.35,95 \% \mathrm{Cl}=1.43-3.86)$ and obesity $\mathrm{AOR}=2.19,95 \% \mathrm{Cl}=1.48-4.18)$.

Conclusion: The prevalence of depression is high among Sudanese patients with T2DM. Rural residence, unemployment, co-morbidity and obesity are significant risk factors for developing depression among patients with T2DM.
\end{abstract}

Keywords: Prevalence, Depression, T2DM, Risk factors

\section{Introduction}

The number of diabetes mellitus (DM) cases is rising globally, and its prevalence was estimated global population to be $9.3 \%$ (463 million people) of the in 2019 [1]. Its prevalence is expected to reach $10.2 \%$ (578 million people) by 2030 and $10.9 \%$ (700 million people) by 2045 [1]. Urban areas have a higher prevalence $(10.8 \%)$ of DM than rural $(7.2 \%)$ areas do, and high-income countries are affected more (10.4\%) compared with low-income

\footnotetext{
* Correspondence: drsaeedomar@yahoo.com

${ }^{1}$ Faculty of Medicine, Gadarif University, Gadarif, Sudan

Full list of author information is available at the end of the article
}

countries $(4.0 \%)$ [1]. Type 2 DM (T2DM) patients represent the majority of patients suffering from DM, at $90 \%$ [1]. According to the International Diabetes Federation's diabetes atlas for 2019, Sudan is reported among the countries that have a DM prevalence of more than $12 \%$ [1]. Recently, a community based research from Sudan demonstrated relatively higher prevalence rates of T2DM $20.8 \%$ of the studied population, from whom the newly diagnosed T2DM and uncontrolled T2DM, were 10 and $80 \%$ respectively [2].

Depression is growing as a major public health problem, exhibiting a global increase in its prevalence and

C C The Author(s). 2021 Open Access This article is licensed under a Creative Commons Attribution 4.0 International License, which permits use, sharing, adaptation, distribution and reproduction in any medium or format, as long as you give appropriate credit to the original author(s) and the source, provide a link to the Creative Commons licence, and indicate if changes were made. The images or other third party material in this article are included in the article's Creative Commons licence, unless indicated otherwise in a credit line to the material. If material is not included in the article's Creative Commons licence and your intended use is not permitted by statutory regulation or exceeds the permitted use, you will need to obtain permission directly from the copyright holder. To view a copy of this licence, visit http://creativecommons.org/licenses/by/4.0/ The Creative Commons Public Domain Dedication waiver (http://creativecommons.org/publicdomain/zero/1.0/) applies to the data made available in this article, unless otherwise stated in a credit line to the data. 
incidence [3, 4]. This disorder poses a huge financial burden and affects many struggling national healthcare systems [5]. Several studies have reported a significant association between depression and DM [6, 7].

Mental health problems often co-occur in people with $\mathrm{DM}$, as depression is twice as common in patients with DM compared with the general population, and it is associated with poor outcomes [8]. Patients with depressive symptoms have a $37-60 \%$ greater risk of developing DM compared with those without depressive symptoms [9-11]. Moreover, a reciprocal or bidirectional association between DM and depression has been documented in previous studies $[8,10,11]$. The association of depression and DM worsens the general outcome related to DM, impairs adherence to medical treatment [12], decreases quality of life [13] and increases fatality [14]. There are many identified risk factors that increase the possibility of depressive symptoms emerging among patients with DM; these include age, gender, urban residence, glycaemic control, smoking, obesity and family history of depression $[15,16]$.

Several previous studies have shown a high prevalence of depression among patients with DM in different populations in Africa [17-21]. However, few published data on depression and DM exist in Sudan [22, 23]. Patients with DM and depression are vulnerable groups and deserve more effort to shed light on and establish an integrated care system for feasibly and effectively managing such complex patients. Such interventions will be reflected positively in improving prognosis and quality of life. In fact, few published data address this issue in Sudan. Hence, the aims of the current study were to determine the prevalence of depression and its associated factors among patients with T2DM in eastern Sudan.

\section{Study area}

Gadarif is one of 18 states in Sudan, and it is located in the eastern part of the country. It has the second-largest economy in Sudan. Gadarif State has a total population of 1,400,000 people, and it covers an area of approximately $75,263 \mathrm{~km}^{2}$. The state is located between latitudes 14 and 16 North and longitudes 35 and 36 East in the semi-desert tropics. The mosaic of the population mostly comprises Sudanese tribes engaged in agricultural and pastoral activities [24].

\section{Subjects and study design}

A cross-sectional study was conducted in May-November 2019. Patients with T2DM were recruited from the outpatient diabetic clinic in Gadarif Diabetic Center. Gadarif diabetic Center is located in the Gadarif city which provides an outpatient services to all diabetic patients in the state who are already registered or referred to. The services were conducted by a team which include endocrinologist, surgeon, ophthalmologist, psychologist, medical laboratory technicians as well as services for foot care, health education and nutritional advices. All patients with type $2 \mathrm{DM}$ who came to follow up during the study period to Gadarif diabetic centre were considered as the study population.

The systematic random sampling technique was used to select the participant who fulfilled the inclusion criteria. According to the Gadarif Diabetic Center records, there were 734 diabetic patients who visited the Center over six month's period prior to the study. The sampling interval $(\approx 2)$ was assumed by dividing the expected number (734) of diabetic patients to the calculated sample size $(734 / 350 \approx 2)$. Thus, eligible patients were interviewed for every 2 intervals until the required sample size (350) was reached.

Men and women aged 18 years and above were included after agreeing to participate in the research and giving written informed consent. Patients below the age of 18, those patients who had gestational diabetes or type $1 \mathrm{DM}$ and those who refused to participate were excluded.

\section{Data collection and analysis}

Well trained team including two general practitioners, a psychologist and two paramedical staff completed the questionnaire by direct face to face interview and conducted the physical examination under direct supervision of the primary investigators during a usual clinic visit. The minimum sample size was 350 , calculated using the following formula:

$$
\frac{Z^{2} P(1-)}{d^{2}}
$$

The prevalence of depression among DM patients in Sudan was $35.6 \%$ [23], with a $95 \%$ confidence interval (CI) and 5\% precision. The collected data were analysed and correlated with the demographic data of the participants to determine whether the variables significantly correlated with depression among the recruited sample. The questionnaire was used to collect information on the following sociodemographic characteristics: age, sex, education (primary level, middle school and college level), employment (employed or unemployed), socioeconomic status (low, moderate or high), marital status (single, married or divorced), residence (urban or rural), alcohol consumption (never, current or former), smoking (never, current or former), comorbidities (hypertension, ischaemic heart disease, bronchial asthma, rheumatoid arthritis, malignancies and other), history of depression or depression among first-degree relatives. The questionnaire was also used to obtain a detailed history regarding $\mathrm{DM}$, including the duration of $\mathrm{DM}$, 
number of medications, insulin therapy, regular followup, presence of co-morbidities and complications related to DM. The participants' weight and height were measured using standard procedures, and the body mass index (BMI) was computed using the following equation: weight $(\mathrm{kg}) /$ height $\left(\mathrm{m}^{2}\right)$. The World Health Organization classification for BMI was followed which as either underweight $(<18.5 \mathrm{~kg} / \mathrm{m} 2)$, normal weight $(18.5-24.9$ $\mathrm{kg} / \mathrm{m} 2)$, overweight $(25.0-29.9(\mathrm{~kg} / \mathrm{m} 2)$, or obese $(\geq 30.0$ $\left.\mathrm{kg} / \mathrm{m}^{2}\right)$ [25].

The study assessed depression using a validated previously used questionnaire which was the Sudanese version of Arabic translation of the Patient Health Questionnaire, (PHQ-9) [26]. The PHQ-9 is a ninequestion questionnaire that screens for depression and assesses the severity. The PHQ-9 demonstrates high sensitivity (73\%) and a very high specificity (98\%) for diagnosing major depression, based on structured psychiatric interviews [27]. The PHQ-9 score ranges from 0 to 27, with each symptom scored on a scale of from 0 to 3 $(0=$ Not at all, $1=$ several days per week, $2=$ more than half of the days, $3=$ nearly every day). The prevalence of depression was diagnosed with a cut-off score of $\geq 10$, which is the most widely accepted to indicate positive cases of depression [28]. Patients who scored less than $10,10-14,15-19$ and 20 or above were considered to have no depression, moderate, moderately severe, and severe depression, respectively [29]. The participants with a score $\geq 10$ were classified as having depression in the further analysis.

\section{Blood glucose measurement}

A sample of $3 \mathrm{ml}$ of venous blood was collected from each participant by a university- graduated medical laboratory technicians, after adequately disinfected by alcohol swab and the procedure and technique were fully explained. The blood was then drawn in a vacuum blood collection tube containing EDTA, and the sample was transferred to the hospital laboratory department to measure HbA1c levels using an Ichroma machine (Republic of Korea). Glycaemic control was defined as recommended by the American Diabetes Association for no pregnant adults and the International Diabetes Federation [29] as Good glycaemic control was defined as an HbA1c level $<7.0 \%$, where the uncontrolled is considered when HbA1c levels was $\geqslant 7.0 \%$.

\section{Statistical analysis}

Data were analysed with a computer using SPSS for Windows (version 20.0). The chi-square test was used to compare proportions between participants with no depression and those who were diagnosed as having depression among patients with DM. Continuous parametric and nonparametric data were compared with the $t$ test and Mann-Whitney $U$ test, respectively, between the two groups (without depression and with depression). Logistic regression analyses were performed, using depression as the dependent variable. Independent variables (age, sex, BMI, marital status, education, job, socioeconomic status, rural or urban residency, smoking, alcohol consumption, history of depression, family history of depression, control of DM-associated comorbidities) were entered into the model if their univariate $p$ was $<0.20$. Odds ratios (ORs) and $95 \%$ CIs were calculated, and a $p$-value $<0.05$ was considered significant.

\section{Results}

\section{General characteristics}

Three hundred and fifty patients with T2DM were enrolled in the study. The median (interquartile range) age and duration of diabetes were 56.0 (14.0) years and 8 (8) years, respectively. Of the 350 participants, 205 (58.6\%) were women, 261 (74.6\%) were urban residents and 135 (38.6\%) had an education level $\geq$ secondary level. The median (interquartile range) BMI was $25.9(5.8) \mathrm{kg} / \mathrm{m}^{2}$, and $80 \%(22.9 \%)$ of participants were obese (Table 1). The prevalence of depression among patients with T2DM was $35.6 \%$, ranging from mild $(24.3 \%)$ to moderate $(7.4 \%)$, moderately severe $(2.2 \%)$ and severe depression $(1.7 \%)$.

There was no significant difference in the age, gender, residence, education, housing, marital status or alcohol and tobacco use between patients with T2DM who had depression and patients with T2DM who had no depression. In comparison with the patients who had no depression, patients who had depression were nonemployed, had co-morbidity and were obese (Table 2). Logistic regression analysis showed that rural residence (adjusted OR $[\mathrm{AOR}]=2.11,95 \% \mathrm{CI}=1.20-3.72$ ), nonemployment $(\mathrm{AOR}=2.32, \quad 95 \% \mathrm{CI}=1.34-4.00)$, comorbidity ( $\mathrm{AOR}=2.35,95 \% \mathrm{CI}=1.43-3.86)$ and obesity $(\mathrm{AOR}=2.19,95 \% \mathrm{CI}=1.48-4.18)$ were associated with depression among patients with T2DM (Table 3).

\section{Discussion}

The study demonstrated that $35.6 \%$ of patients with T2DM had depression. This is exactly the same to the prevalence $(35.6 \%)$ of depression reported in patients with T2DM in northern Sudan [23]. The prevalence in our study was considerably lower than the prevalence of depression $(44 \%)$ in patients with T2DM in Omdurman, Sudan [22]. The prevalence of depression in this study was markedly higher than the global prevalence of depression (28\%) among patients with T2DM [30]. At the same time, the prevalence of depression in this study was relatively lower than the prevalence rates of depression among patients with T2DM in Ethiopia (44.7\%) 
Table 1 Sociodemographic and clinical characteristics of patients with type 2 diabetes in eastern Sudan

\begin{tabular}{|c|c|c|c|}
\hline Variable & & Frequency & Proportion \\
\hline \multirow[t]{2}{*}{ Gender } & Female & 205 & 58.6 \\
\hline & Male & 145 & 41.4 \\
\hline \multirow[t]{2}{*}{ Residence } & Urban & 261 & 74.6 \\
\hline & Rural & 89 & 25.4 \\
\hline \multirow[t]{2}{*}{ Education level } & $<$ Secondary & 215 & 61.4 \\
\hline & $\geq$ Secondary & 135 & 38.6 \\
\hline \multirow[t]{2}{*}{ Marital status } & Married & 322 & 92.0 \\
\hline & Single/divorced & 28 & 8.0 \\
\hline \multirow[t]{2}{*}{ Job } & Employed & 141 & 40.3 \\
\hline & Non-employed & 209 & 59.7 \\
\hline \multirow[t]{3}{*}{ Income } & Low & 202 & 57.7 \\
\hline & Moderate & 130 & 37.1 \\
\hline & High & 18 & 5.1 \\
\hline \multirow[t]{2}{*}{ Housing } & With family & 343 & 98.0 \\
\hline & With friends & 7 & 2.0 \\
\hline \multirow[t]{3}{*}{ Tobacco use } & Never & 302 & 86.3 \\
\hline & Current & 19 & 5.4 \\
\hline & Former & 29 & 8.3 \\
\hline \multirow[t]{3}{*}{ Alcohol } & Never & 335 & 95.7 \\
\hline & Current & 1 & .3 \\
\hline & Former & 14 & 4.0 \\
\hline \multirow[t]{2}{*}{ Participant's mental illness } & Yes & 24 & 6.9 \\
\hline & No & 326 & 93.1 \\
\hline \multirow[t]{2}{*}{ First degree mental illness } & Yes & 23 & 6.6 \\
\hline & No & 327 & 93.4 \\
\hline \multirow[t]{2}{*}{ Presence of co-morbidity } & Yes & 142 & 40.6 \\
\hline & No & 208 & 59.4 \\
\hline \multirow[t]{4}{*}{ Body mass index groups, $\mathrm{kg} / \mathrm{m}^{2}$} & Underweight & 8 & 2.3 \\
\hline & Normal & 134 & 38.3 \\
\hline & Overweight & 128 & 36.6 \\
\hline & Obese & 80 & 22.9 \\
\hline \multirow[t]{2}{*}{ Uncontrolled diabetes } & Yes & 306 & 87.4 \\
\hline & No & 44 & 12.6 \\
\hline
\end{tabular}

[31] and in Rwanda (83.8\%) [21]. However, the prevalence in our study was considerably higher than the prevalence rates of depression among patients with T2DM in Ghana (31.3\%) [19] and Malawi (18\%) [32]. The different prevalence rates obtained in these studies may be explained by the different methods used, including differences in the sample size, screening tools used for depression, different cut-off scores employed and sociodemographic statuses among the participants. A higher prevalence of depression among patients with DM may indicate a strong association between the two conditions, as both diseases might have a common aetiology [33]. Hence, the presence of DM increases the prevalence or risk for future depression, and at the same time, the presence of depression increases the potential risk for future DM [33]. In addition, chronic stress has behavioural consequences as a result of stress hormone secretion, which increases the risk for both depression and DM [34]. Interestingly, patients with either DM or depression are vulnerable to neurodegenerative processes that are associated with structural changes in the prefrontal cortex and hippocampus [35, 36]. The results of these changes are cerebral atrophy and recurrent 
Table 2 Comparing frequency (proportion) of the sociodemographic characteristics of patients who had depression and patients who had no depression in eastern Sudan

\begin{tabular}{|c|c|c|c|c|}
\hline Variable & & Patient with depression $(N=87)$ & Patient who had no depression $(N=263)$ & $p$ \\
\hline \multirow[t]{2}{*}{ Gender } & Female & $51(58.6)$ & $154(58.6)$ & 1.000 \\
\hline & Male & $36(41.4)$ & $109(41.4)$ & \\
\hline \multirow[t]{2}{*}{ Residence } & Urban & $58(66.7)$ & $203(77.2)$ & 0.064 \\
\hline & Rural & $29(33.3)$ & $60(22.8)$ & \\
\hline \multirow[t]{2}{*}{ Education level } & $<$ Secondary & $57(65.5)$ & $158(60.1)$ & 0.377 \\
\hline & $\geq$ Secondary & $30(34.5)$ & $105(39.9)$ & \\
\hline \multirow[t]{2}{*}{ Marital status } & Married & $82(5.7)$ & $240(8.7)$ & 0.496 \\
\hline & Single/divorced & $5(94.3)$ & $23(91.3)$ & \\
\hline \multirow[t]{2}{*}{ Job } & Employed & $23(26.4)$ & $118(44.9)$ & 0.002 \\
\hline & Non-employed & $64(73.6)$ & $145(55.1)$ & \\
\hline \multirow[t]{3}{*}{ Income } & Low & $50(57.5)$ & $152(57.8)$ & 0.683 \\
\hline & Moderate & $34(39.1)$ & $96(36.5)$ & \\
\hline & High & $3(3.4)$ & $15(5.7)$ & \\
\hline \multirow[t]{2}{*}{ Housing } & With family & $86(98.9)$ & $257(97.7)$ & 1.000 \\
\hline & With friends & $1(1.1)$ & $6(2.3)$ & \\
\hline \multirow[t]{3}{*}{ Tobacco use } & Never & $74(85.1)$ & $228(86.7)$ & 0.784 \\
\hline & Current & $6(6.9)$ & $13(4.9)$ & \\
\hline & Former & $7(8.0)$ & $22(8.4)$ & \\
\hline \multirow[t]{3}{*}{ Alcohol } & Never & $83(95.4)$ & $252(95.8)$ & 0.804 \\
\hline & Current & $0(0.0)$ & $1(0.4)$ & \\
\hline & Former & $4(4.6)$ & $10(3.8)$ & \\
\hline \multirow[t]{2}{*}{ Mental illness } & Yes & $4(4.6)$ & $20(7.6)$ & 0.464 \\
\hline & No & $83(95.4)$ & $243(92.4)$ & \\
\hline \multirow[t]{2}{*}{ First degree mental illness } & Yes & $5(5.7)$ & $18(6.8)$ & 1.000 \\
\hline & No & $82(94.3)$ & $245(93.2)$ & \\
\hline \multirow[t]{2}{*}{ Presence of co-morbidity } & Yes & $49(56.3)$ & $93(35.4)$ & 0.001 \\
\hline & No & $38(43.7)$ & $170(64.6)$ & \\
\hline \multirow[t]{4}{*}{ Body mass index (BMI) groups } & Underweight & $3(3.4)$ & $5(1.9)$ & 0.018 \\
\hline & Normal & $28(32.2)$ & $106(40.3)$ & \\
\hline & Overweight & $26(29.9)$ & $102(38.8)$ & \\
\hline & Obese & $30(34.5)$ & $50(19.0)$ & \\
\hline \multirow[t]{2}{*}{ Uncontrolled diabetes } & Yes & $78(89.7)$ & $228(86.7)$ & 0.577 \\
\hline & No & $9(10.3)$ & 35 (13.3) & \\
\hline
\end{tabular}

infarcts and cerebral blood flow changes of both hypo- and hyper-perfusion [35, 36].

This study showed that rural residents with T2DM had a 2.11 times higher risk of depression. This was in accordance with the results obtained in Kenya, where depression was prevalent among rural people with DM [37]. This may reflect rural-urban health disparities in Africa because rural dwellers were more likely to be older, have lower education levels, have poverty and have less cognitive functioning compared with urban dwellers [38]. In contrast, depressive symptoms were more prevalent among urban residents with T2DM in Guinea [39]. A higher risk of depression may be related to the interaction between urbanicity, the socio-ecological environment and mental health.

Our study showed that the unemployed were at higher risk for depression among patients with T2DM. Several studies conducted in African countries, such as South Africa [40], Guinea [39] and Rwanda [21], have shown that unemployment is a significant risk factor for depression in patients with T2DM. 
Table 3 Multivariate (non-adjusted and adjusted) analysis of the factors associated with depression among patients with type 2 diabetes in eastern Sudan

\begin{tabular}{|c|c|c|c|c|c|c|c|}
\hline Variable & & Non-adjusted & & & Adjusted & & \\
\hline & & Odds ratio $(\mathrm{OR})$ & 95\% confidence interval (Cl) & $p$ & OR & $95 \% \mathrm{Cl}$ & $p$ \\
\hline \multirow[t]{2}{*}{ Residence } & Urban & Reference & & & Reference & & \\
\hline & Rural & 2.23 & $1.25-3.98$ & 0.006 & 2.11 & $1.20-3.72$ & 0.009 \\
\hline \multirow[t]{2}{*}{ Job } & Employed & Reference & & & Reference & & \\
\hline & Non-employed & 2.30 & $1.32-4.02$ & 0.003 & 2.32 & $1.34-4.00$ & 0.002 \\
\hline \multirow[t]{2}{*}{ Presence of co-morbidity } & Yes & 2.56 & $1.51-4.34$ & $<0.001$ & 2.35 & $1.43-3.86$ & 0.001 \\
\hline & No & Reference & & & Reference & & \\
\hline \multirow[t]{4}{*}{ Body mass index (BMI) groups } & Underweight & 2.46 & $0.52-11.63$ & 0.255 & 2.75 & $0.59-12.71$ & 0.193 \\
\hline & Normal & Reference & & & Reference & & \\
\hline & Overweight & 0.99 & $0.52-1.86$ & 0.982 & 0.98 & $0.52-1.83$ & 0.959 \\
\hline & Obese & 2.08 & $1.08-3.99$ & 0.028 & 2.19 & $1.48-4.18$ & 0.017 \\
\hline
\end{tabular}

In the current study, obese patients had a 2.19 times higher likelihood of developing depression among patients with T2DM. Similar findings of significant associations between obesity and depression in participants with T2DM were observed in Ethiopia [31] and Guinea [39]. In contrast, another study failed to show an association between obesity and depression among patients with T2DM in Ghana [19]. The association between obesity and depression may be explained in that the two diseases share common biological pathways [41]. The depression-obesity link involves genetics, alterations in systems involved in homeostatic adjustments and brain circuitries integrating homeostatic and mood regulatory responses [41]. Moreover, the homeostatic adjustments depend on the hypothalamus-pituitary-adrenal axis, immuno-inflammatory activation and neuroendocrine regulators of energy metabolism, such as insulin, leptin and the gut microbiome [41].

There was no association between depression and age in the current study. Similar findings in previous studies showed no association between depression and age in central Sudan, Omdurman [22], Tanzania [20], Ethiopia [42] and Nigeria [43]. A meta-analysis of patients with T2DM revealed that depression was more prevalent in subjects younger than 65 compared with older people [30]. Depression among older patients with DM may be a consequence of the neurodegenerative processes that potentiate the risk of depression $[35,36]$.

Our study showed no significant association between gender and depression among patients with T2DM. A similar lack of association was observed among patients with T2DM in northern [23] and central Sudan [22], as well as in Malawi [32]. In contrast, gender was reported as a significant risk for depression among patients with T2DM in South Africa [40], Guinea [39], Ghana [19] and Rwanda [21]. A predominance of female gender is proposed by cognitive vulnerability-stress models of depression, and this is characterised by higher levels of negative cognitive style and stress in girls than boys beginning in early adolescence [44].

Our study showed that glycaemic control was not a significant risk for developing depression among patients with T2DM. This is a similar outcome to the nonsignificant association of depression and glycaemic control using fasting blood sugar as reference in patients with T2DM found in Ethiopia [31, 45] and subjects with DM in Nigeria [43]. In contrast, a significant difference between depression and poor glycaemic control (HbA1c > 7\%) among patients with DM was documented in Sudan [23], Guinea [39], Ghana [19] and South Africa [40]. It is recognised that a high level of HbA1c is a significant predictor of hippocampal volume [46], and this leads to similar neurodegenerative processes to those associated with depression [36].

\section{Limitations of the study}

The limitations of this study are that it is a facility based which may not reflect the prevalence among the community diabetic patients and the cross-sectional nature of the study. In addition, the use of the PHQ-9 psychiatric scale is not the gold standard scale to assess depression.

\section{Conclusion}

The prevalence of depression is high among Sudanese patients with T2DM. Rural residence, unemployment, co-morbidity and obesity appear to be significant risk factors for developing depression among patients with T2DM. Hence, efforts to minimise the burden of depression and improve the future of DM in Sudan are highly recommended.

\section{Abbreviations}

BMI: Body mass index; OR: Odds ratio; Cl: Confidence interval; PHQ: Patient health questionnaire; T2DM: Type 2 diabetes mellitus 


\section{Acknowledgements}

We would like to thank the patients for participating in this study.

\section{Authors' contributions}

SMO, IRM and IA conceived and designed the study. SMO and MBI recruited the participants. IRM, MBI and IA analysed the data and wrote the manuscript. All contributing authors of this original manuscript authorised the final version of the manuscript. All authors read and approved the final manuscript.

\section{Funding}

None received.

\section{Availability of data and materials}

The datasets used and/or analysed during the current study are available from the corresponding author on reasonable request.

\section{Declarations}

\section{Ethics approval and consent to participate}

The study received ethical approval from the Research Board of the Faculty of Medicine, University of Gadarif, Sudan. The reference number is 2019, \#7. Written informed consent was obtained from all the enrolled patients, in accordance with the Human Rights Declaration of Helsinki.

\section{Consent for publication}

Not applicable.

\section{Competing interests}

The authors declare that they have no competing interests.

\section{Author details}

${ }^{1}$ Faculty of Medicine, Gadarif University, Gadarif, Sudan. ${ }^{2}$ Royal Commission Hospital, Al Jubail Industrial City, Al Jubail, Kingdom of Saudi Arabia. ${ }^{3}$ Department of Obstetrics and Gynecology, Unaizah College of Medicine and Medical Sciences, Qassim University, Unaizah, Saudi Arabia.

Received: 16 March 2021 Accepted: 29 June 2021

Published online: 06 July 2021

\section{References}

1. IDF Diabetes Atlas 9th edition 2019. https://www.diabetesatlas.org/en/. Acessed:2021-06-04.

2. Omar SM, Musa IR, ElSouli A, Adam I. Prevalence, risk factors, and glycaemic control of type 2 diabetes mellitus in eastern Sudan: a community-based study. Ther Adv Endocrinol Metab. 2019:10:2042018819860071.

3. Ferrari AJ, Charlson FJ, Norman RE, Patten SB, Freedman G, Murray CJL, et al. Burden of depressive disorders by country, sex, age, and year: findings from the global burden of disease study 2010. PLoS Med. 2013;11:e1001547.

4. Fu TST, Lee CS, Gunnell D, Lee WC, Cheng ATA. Changing trends in the prevalence of common mental disorders in Taiwan: a 20-year repeated cross-sectional survey. Lancet. 2013;381(9862):235-41. https://doi.org/10.101 6/S0140-6736(12)61264-1.

5. Murray CJL, Vos T, Lozano R, Naghavi M, Flaxman AD, Michaud C, et al. Disability-adjusted life years (DALYs) for 291 diseases and injuries in 21 regions, 1990-2010: a systematic analysis for the global burden of disease study 2010. Lancet. 2012;380(9859):2197-223. https://doi.org/10.1016/S01406736(12)61689-4

6. Talbot F, Nouwen A. A review of the relationship between depression and diabetes in adults: is there a link? Diabetes Care. 2000;23(10):1556-62. https://doi.org/10.2337/diacare.23.10.1556.

7. Carnethon MR, Kinder LS, Fair JM, Stafford RS, Fortmann SP. Symptoms of depression as a risk factor for incident diabetes: findings from the National Health and nutrition examination epidemiologic follow-up study, 19711992. Am J Epidemiol. 2003;158(5):416-23. https://doi.org/10.1093/aje/kwg1 72.

8. Anderson RJ, Freedland KE, Clouse RE, Lustman PJ. The prevalence of comorbid depression in adults with diabetes: a meta-analysis. Diabetes Care. 2001;24(6):1069-78. https://doi.org/10.2337/diacare.24.6.1069.

9. Knol MJ, Twisk JWR, Beekman ATF, Heine RJ, Snoek FJ, Pouwer F. Depression as a risk factor for the onset of type 2 diabetes mellitus. A meta- analysis. Diabetologia. 2006;49(5):837-45. https://doi.org/10.1007/s00125006-0159-x.

10. Mezuk B, Eaton WW, Albrecht S, Golden SH. Depression and type 2 diabetes over the lifespan: a meta-analysis. Diabetes Care. 2008;31(12):2383-90. https://doi.org/10.2337/dc08-0985.

11. Rotella F, Mannucci E. Depression as a risk factor for diabetes: a metaanalysis of longitudinal studies. J Clin Psychiatry. 2013;74(01):31-7. https:// doi.org/10.4088/JCP.12r07922.

12. Gonzalez JS, Peyrot M, McCarl LA, Collins EM, Serpa L, Mimiaga MJ, et al. Depression and diabetes treatment nonadherence: a meta-analysis. Diabetes Care. 2008;31(12):2398-403. https://doi.org/10.2337/dc08-1341.

13. Baumeister $H$, Hutter N, Bengel J, Härter M. Quality of life in medically ill persons with comorbid mental disorders: a systematic review and metaanalysis. Psychother Psychosom. 2011;80(5):275-86. https://doi.org/10.1159/ 000323404.

14. Egede LE, Nietert PJ, Zheng D. Depression and all-cause and coronary heart disease mortality among adults with and without diabetes. Diabetes Care 2005;28(6):1339-45. https://doi.org/10.2337/diacare.28.6.1339.

15. Chireh B, D'Arcy C. Shared and unique risk factors for depression and diabetes mellitus in a longitudinal study, implications for prevention: an analysis of a longitudinal population sample aged $\geqslant 45$ years. Ther Adv Endocrinol Metab. 2019;10:2042018819865828.

16. Kamrul-Hasan AB, Palash-Molla M, Mainul-Ahsan M, Gaffar AJ, Asaduzzaman $M$, Saifuddin $M$, et al. Prevalence and predictors of depression among patients with type 2 diabetes: a multicenter cross-sectional study from Bangladesh. Mymensingh Med J. 2019;28(1):23-30.

17. Jansen van Vuuren JM, Pillay S. Major depressive disorder in patients with diabetes mellitus in Pietermaritzburg, South Africa. S Afr Med J. 2018;109:58-61.

18. Akena D, Kadama P, Ashaba S, Akello C, Kwesiga B, Rejani L, et al. The association between depression, quality of life, and the health care expenditure of patients with diabetes mellitus in Uganda. J Affect Disord. 2015;174:7-12. https://doi.org/10.1016/j.jad.2014.11.019.

19. Akpalu J, Yorke E, Ainuson-Quampah J, Balogun W, Yeboah K. Depression and glycaemic control among type 2 diabetes patients: , cross-sectional study in a tertiary healthcare facility in Ghana. BMC Psychiatry. 2018;18(1): 357. https://doi.org/10.1186/s12888-018-1933-2.

20. Khan ZD, Lutale J, Moledina SM. Prevalence of Depression and Associated Factors among Diabetic Patients in an Outpatient Diabetes Clinic. Psychiatry J. 2019;2019:2083196.

21. Mukeshimana M, Chironda G. Depression and associated factors among the patients with type 2 diabetes in Rwanda. Ethiop J Health Sci. 2019;29(6): 709-18. https://doi.org/10.4314/ejhs.v29i6.7.

22. Mirghani HO. Distress and psychopathology among Sudanese patients with type 2 diabetes mellitus and its relation to glycaemic control. J Taibah Univ Med Sci. 2017:12:298-303.

23. Osman Abdelaziz M, Ali Alzain M, Abdal-mageed Abdalkhaleg M, Abdalmageed Abdalkhaleg M, M Ibnouf MA. Prevalence and Risk Factors of Depression among Adult Type 2 Diabetic Patients at Al-Jemaih Diabetic Center. Sudan J Med Sci. 2020;15:408-17.

24. Eldigail MH, Adam GK, Babiker RA, Khalid F, Adam IA, Omer OH, et al. Prevalence of dengue fever virus antibodies and associated risk factors among residents of El-Gadarif state, Sudan. BMC Public Health. 18(1):921.

25. World Health Organization. Obesity: preventing and managing the global epidemic. Report of a WHO consultation. 2000. https://www.who.int/ nutrition/publications/obesity/WHO_TRS_894/en/. Acessed:2021-06-04.

26. Becker S, Al Zaid K, Al FE. Screening for somatization and depression in Saudi Arabia: a validation study of the PHQ in primary care. Int J Psychiatry Med. 2002;32(3):271-83. https://doi.org/10.2190/XTDD-8L18-P9E0-JYRV.

27. Spitzer RL, Kroenke K, Williams JBW. Validation and utility of a self-report version of PRIME-MD: the PHQ primary care study. J Am Med Assoc. 1999; 282(18):1737-44. https://doi.org/10.1001/jama.282.18.1737.

28. Hermanns N, Kulzer B, Krichbaum M, Kubiak T, Haak T. How to screen for depression and emotional problems in patients with diabetes: comparison of screening characteristics of depression questionnaires, measurement of diabetes-specific emotional problems and standard clinical assessment. Diabetologia. 2006;49(3):469-77. https://doi.org/10.1007/s00125-005-0094-2.

29. Kroenke K, Spitzer RL, Williams JBW. The PHQ-9: validity of a brief depression severity measure. J Gen Intern Med. 2001;16(9):606-13. https://doi.org/10.1 046/j.1525-1497.2001.016009606.x.

30. Khaledi M, Haghighatdoost F, Feizi A, Aminorroaya A. The prevalence of comorbid depression in patients with type 2 diabetes: an updated 
systematic review and meta-analysis on huge number of observational studies. Acta Diabetol. 2019;56(6):631-50. https://doi.org/10.1007/s00592-01 9-01295-9.

31. Habtewold TD, Alemu SM, Haile YG. Sociodemographic, clinical, and psychosocial factors associated with depression among type 2 diabetic outpatients in black lion general specialized hospital, Addis Ababa. Ethiopia: A cross-sectional study BMC Psychiatry. 2016;16:103.

32. Udedi M, Pence BW, Stewart RC, Muula AS. Detection and prevalence of depression among adult type 2 diabetes mellitus patients attending noncommunicable diseases clinics in Lilongwe, Malawi. Int J Ment Health Syst. 2020;14(1):79. https://doi.org/10.1186/s13033-020-00413-3.

33. Bădescu SV, Tătaru C, Kobylinska L, Georgescu EL, Zahiu DM, Zăgrean AM, et al. The association between diabetes mellitus and depression. J Med Life. 2016;9(2):120-5.

34. Moulton CD, Costafreda SG, Horton P, Ismail K, Fu CHY. Meta-analyses of structural regional cerebral effects in type 1 and type 2 diabetes. Brain Imag Behav. 2015;9(4):651-62. https://doi.org/10.1007/s11682-014-9348-2.

35. Van Harten B, De Leeuw FE, Weinstein HC, Scheltens P, Biessels GJ. Brain imaging in patients with diabetes: a systematic review. Diabetes Care. 2006; 29(11):2539-48. https://doi.org/10.2337/dc06-1637.

36. Sapolsky RM. Depression, antidepressants, and the shrinking hippocampus, Proc Natl Acad Sci U S A. 2001;98(22):12320-2. https://doi.org/10.1073/pna s.231475998.

37. Shirey K, Manyara SM, Atwoli L, Tomlin R, Gakinya B, Cheng S, et al. Symptoms of depression among patients attending a diabetes care clinic in rural western Kenya. J Clin Transl Endocrinol. 2015;2(2):51-4. https://doi. org/10.1016/j.jcte.2015.02.002

38. Peltzer K, Phaswana-Mafuya N, Pengpid S. Rural-urban health disparities among older adults in South Africa. African J Prim Heal Care Fam Med. 2019;11:1890.

39. Camara A, Baldé NM, Enoru S, Bangoura JS, Sobngwi E, Bonnet F. Prevalence of anxiety and depression among diabetic African patients in Guinea: association with HbA1c levels. Diabetes Metab. 2015;41(1):62-8. https://doi.org/10.1016/j.diabet.2014.04.007.

40. Ramkisson S, Joseph Pillay B, Sartorius B. Diabetes distress and related factors in south African adults with type 2 diabetes. J Endocrinol Metab Diabetes South Africa. 2016;21(2):35-9. https://doi.org/10.1080/16089677.201 6.1205822 .

41. Milaneschi Y, Simmons WK, van Rossum EFC, Penninx BW. Depression and obesity: evidence of shared biological mechanisms. Mol Psychiatry. 2019; 24(1):18-33. https://doi.org/10.1038/s41380-018-0017-5.

42. Asefa A, Zewudie A, Henok A, Mamo Y, Nigussie T. Depression and its associated factors among diabetes mellitus patients attending selected hospitals in Southwest Ethiopia: a cross-sectional study. Psychiatry J. 2020; 2020:1-8. https://doi.org/10.1155/2020/6486030

43. Edah JO, Goar SG, Odoh G, Lawal B, Dayom PS, Sunday ZF, et al. Undiagnosed depression among adults with diabetes mellitus in Jos. Niger J Clin Pract. 2020;23(10):1431-6. https://doi.org/10.4103/njcp.njcp_155_20.

44. Salk RH, Hyde JS, Abramson LY. Gender differences in depression in representative national samples: meta-analyses of diagnoses and symptoms. Psychol Bull. 2017;143(8):783-822. https://doi.org/10.1037/bul0000102.

45. Engidaw NA, Wubetu AD, Basha EA. Prevalence of depression and its associated factors among patients with diabetes mellitus at Tirunesh-Beijing general hospital, Addis Ababa, Ethiopia. BMC Public Health. 2020;20(1):266. https://doi.org/10.1186/s12889-020-8360-2

46. Gold SM, Dziobek I, Sweat V, Tirsi A, Rogers K, Bruehl H, et al. Hippocampal damage and memory impairments as possible early brain complications of type 2 diabetes. Diabetologia. 2007;50(4):711-9. https://doi.org/10.1007/ s00125-007-0602-7.

\section{Publisher's Note}

Springer Nature remains neutral with regard to jurisdictional claims in published maps and institutional affiliations.

Ready to submit your research? Choose BMC and benefit from:

- fast, convenient online submission

- thorough peer review by experienced researchers in your field

- rapid publication on acceptance

- support for research data, including large and complex data types

- gold Open Access which fosters wider collaboration and increased citations

- maximum visibility for your research: over $100 \mathrm{M}$ website views per year

At BMC, research is always in progress.

Learn more biomedcentral.com/submissions 